\title{
Implicit Perceptual Memory Modulates Early Visual Processing of Ambiguous Images
}

\author{
Maartje C. de Jong, ${ }^{1}$ Jan W. Brascamp, ${ }^{1}$ Chantal Kemner, ${ }^{1,2,3}$ Raymond van Ee, ${ }^{4,5,6}$ and ${ }^{\circledR}$ Frans A. J. Verstraten ${ }^{1,7}$ \\ ${ }^{1}$ Helmholtz Institute and ${ }^{2}$ Department of Developmental Psychology, Utrecht University, 3508 TC Utrecht, The Netherlands, ${ }^{3}$ Department of Child and \\ Adolescent Psychiatry, Rudolf Magnus Institute of Neuroscience, University Medical Centre, 3584 CX Utrecht, The Netherlands, ${ }^{4}$ Philips Research \\ Laboratories, Department of Brain, Body, and Behavior, 5656 AE Eindhoven, The Netherlands, ${ }^{5}$ Laboratory of Experimental Psychology, University of \\ Leuven, 3000 Leuven, Belgium, ${ }^{6}$ Donders Institute, Department of Biophysics, Radboud University, 6500 GL Nijmegen, The Netherlands, and ${ }^{7}$ University of \\ Sydney, Faculty of Science, School of Psychology, Sydney, NSW 2006, Australia
}

The way we perceive the present visual environment is influenced by past visual experiences. Here we investigated the neural basis of such experience dependency. We repeatedly presented human observers with an ambiguous visual stimulus (structure-from-motion) that can give rise to two distinct perceptual interpretations. Past visual experience is known to influence the perception of such stimuli. We recorded fast dynamics of neural activity shortly after stimulus onset using event-related electroencephalography. The number of previous occurrences of a certain percept modulated early posterior brain activity starting as early as $50 \mathrm{~ms}$ after stimulus onset. This modulation developed across hundreds of percept repetitions, reflecting several minutes of accumulating perceptual experience. Importantly, there was no such modulation when the mere number of previous stimulus presentations was considered regardless of how they were perceived. This indicates that the effect depended on previous perception rather than previous visual input. The short latency and posterior scalp location of the effect suggest that perceptual history modified bottom-up stimulus processing in early visual cortex. We propose that bottom-up neural responses to a given visual presentation are shaped, in part, by feedback modulation that occurred during previous presentations, thus allowing these responses to be biased in light of previous perceptual decisions.

Key words: ambiguous figures; EEG; perceptual memory; perceptual rivalry; vision; visual cortex

\section{Introduction}

An essential attribute of our sensory systems is that past neural processing affects present neural activity. In the adult brain, the response properties of sensory neurons are continually tuned to the current sensory environment (Clifford et al., 2007; Thompson and Burr, 2009; Chopin and Mamassian, 2012). Previous visual input and its associated perception can influence both later perception (Leopold et al., 2002; Maier et al., 2003; Pearson and Brascamp, 2008) and neural processing (Kornmeier and Bach, 2006; Pitts and Britz, 2011; de Jong et al., 2012b). To study the neural effects of previous perception specifically, we here measured electroencephalograms (EEGs) while participants viewed an ambiguous visual stimulus. Because ambiguous stimuli can be

\footnotetext{
Received June 7, 2013; revised June 9, 2014; accepted June 15, 2014.

Author contributions: M.C.d.J. and J.W.B. designed research; M.C.d.J. performed research; M.C.d.J., C.K., R.v.E., and F.A.J.V. contributed unpublished reagents/analytic tools; M.C.d.J. analyzed data; M.C.d.J., J.W.B., R.v.E., and F.A.J.V. wrote the paper.

M.C.d.J. and F.A.J.V. were supported by the Netherlands Organization for Scientific Research. M.C.d.J. and R.v.E. were supported by a Utrecht University High Potential grant. J.W.B. was supported by a Veni grant from the Netherlands Organization for Scientific Research. R.v.E. was also supported by a grant from the Flemish Methusalem program (METH/08/02 assigned to J. Wagemans). We thank Esther Holleman and Gerben Klein for their assistance and Casper Erkelens for helpful discussion.

The authors declare no competing financial interests.

Correspondence should be addressed to Maartje C. de Jong, Heidelberglaan 1, 3508 TC Utrecht, The Netherlands. E-mail: dejongmc@gmail.com.

DOI:10.1523/JNEUROSCI.2413-13.2014

Copyright $\odot 2014$ the authors $\quad 0270-6474 / 14 / 349970-12 \$ 15.00 / 0$
}

perceived in multiple ways while visual stimulation remains constant, they allow a partial dissociation between stimulation and perception (Fig. 1A).

How an ambiguous stimulus is perceived, depends strongly on previous perception of that stimulus (Orbach et al., 1963; Leopold et al., 2002; Maier et al., 2003; Pearson and Brascamp, 2008). This dependence includes both a short-term effect of the latest percept experienced just before the current one but also a longer-term effect of perception during the past minutes (Pastukhov and Braun, 2008; Pearson and Brascamp, 2008; Brascamp et al., 2009; de Jong et al., 2012a). Existing EEG studies have focused on the short-term influence of the latest presentation (Kornmeier and Bach, 2004, 2005, 2006; Pitts and Britz, 2011). These studies generally compared cases in which two consecutive stimulus presentations yield identical perception to cases in which they yield different perception, revealing differential EEG activity starting from $130 \mathrm{~ms}$ after stimulus onset. Here we specifically investigate the neural mechanism by which a minutes-long perceptual history can influence current perception.

Behaviorally, the effect of long-term perceptual history tends to be facilitatory, leading to reoccurrence of the percept that was experienced most in the recent past (Pearson and Brascamp, 2008). In contrast, the aftereffect of previous stimulation is usually suppressive, causing a perceptual bias away from the features of previous stimulation (Long and Toppino, 2004; Pearson and 
A
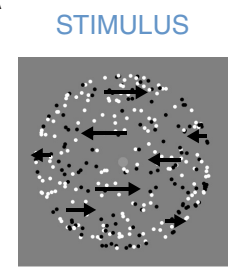

PERCEPTION

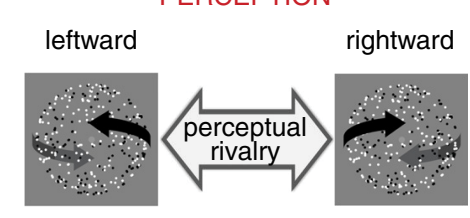

B

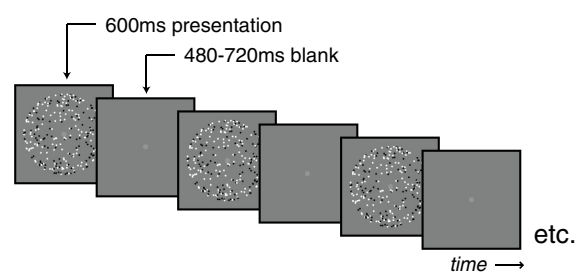

C

Events during an experimental session:

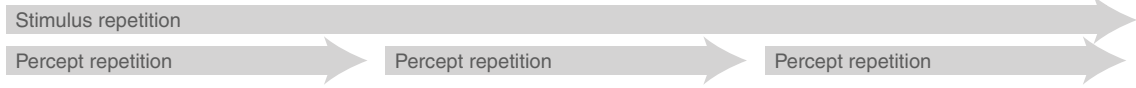

STIMULUS:

presentation

$\downarrow$ blank

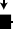

$-1$

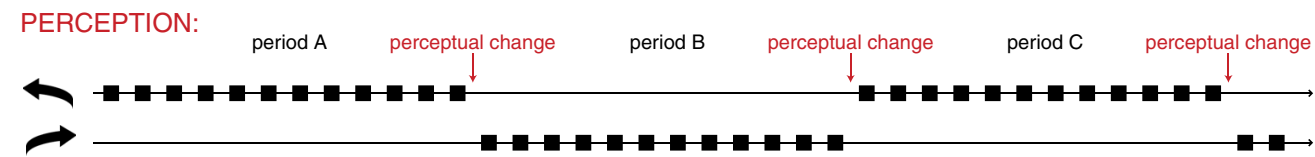

D

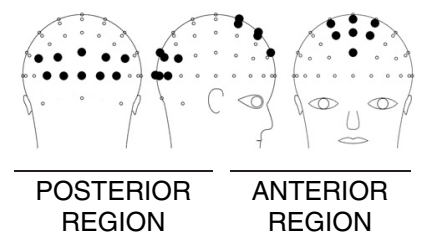

E

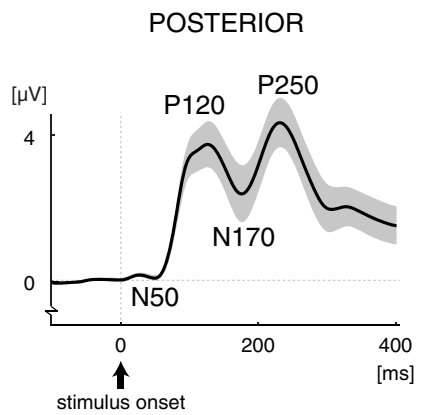

time [minutes] 
onset, suggesting that long-term perceptual history modified bottom-up stimulus processing.

\section{Materials and Methods}

Participants. There were 21 participants ( 13 females, eight males) who all gave written informed consent before participation and who had normal or corrected-to-normal vision and no neurological history. Four participants (one female, three males) were excluded because their perceptual time courses were not sufficiently stable for our analysis (see criteria in the following sections). All experiments were carried out in accordance with the ethical guidelines in the Declaration of Helsinki (2000) of the World Medical Association.

Stimulus. An ambiguous structure-from-motion stimulus that consisted of 350 dots (each $0.077^{\circ}$ in diameter) was presented in the center of a computer screen $(75 \mathrm{~Hz}$ refresh rate) on a gray background. The dots were either black or white, had unlimited lifetime, and represented random points on the surface of a virtual globe $\left(5.0^{\circ}\right.$ in diameter; viewing distance was $107 \mathrm{~cm}$; Fig. 1A). The dots moved leftward or rightward, and their speed on the screen was fastest in the middle of the stimulus and slowest near the left and right edges (at the edges the motion direction reversed). The sinusoidal speed profile of the dots created the percept of a globe revolving around its vertical axis every $7.8 \mathrm{~s}$. The threedimensional interpretation of the stimulus, and thereby its direction of rotation, was ambiguous, because no depth cues differentiated the rightward-moving surface from the leftward-moving surface.

An experimental session consisted of $600 \mathrm{~ms}$ presentations of the rotating globe interleaved with blank intervals with a duration that was randomly selected of 10 evenly spaced fixed values between 480 and 720 $\mathrm{ms}$ (duration was $600 \mathrm{~ms}$ on average; Fig. 1B). During the stimulus presentations and the blank intervals, a centrally presented green fixation dot remained visible that subtended $0.18^{\circ}$ of visual angle. Presentation durations were sufficiently brief to minimize the occurrence of changes in perceived rotation direction within one presentation epoch. The stimuli were created using Mathematica (Wolfram Research) and Presentation (Neurobehavioral Systems).

Procedure. Participants were instructed to maintain strict fixation on the fixation dot throughout the experimental session. At every stimulus presentation, the participants indicated the direction of motion of the surface that was perceived to be in front by pressing one of two corresponding buttons using their corresponding hand. They refrained from responding when they could not differentiate the front from the back surface.

Although the stimulus was the same on every presentation, the perceptual interpretation changed occasionally. The participants reported minutes-long periods of repeated perception of one rotation direction of the globe after which perception would switch and the other rotation direction would be experienced for the next period (Fig. 1C). This is consistent with existing findings (Orbach et al., 1963; Leopold et al., 2002). An experimental session was terminated when three perceptually stable periods were completed (see below for our definition of a stable period). These three consecutive periods are hereafter referred to as periods $\mathrm{A}, \mathrm{B}$, and $\mathrm{C}$. Most participants completed three experimental sessions. Two of the participants completed only one session, and two others completed only two sessions because of technical and practical limitations. During the break between sessions, the participants were free to rest and/or walk around. The break lasted at least as long as the previous experimental block and was intended for recovery from adaptation/ mnemonic traces that were built up during the previous session (sessions lasted 14 min on average).

Analysis of perceptual stabilization. The perceptual time courses of the individual participants were analyzed using MATLAB (MathWorks). For each stimulus presentation, manual responses occurring between 133 (eight screen refresh intervals) and $1000 \mathrm{~ms}$ after stimulus onset were recorded. Presentations to which no response was recorded were excluded from additional analysis (5.6\% of presentations were excluded on average across participants). We also excluded the first $30 \mathrm{~s}$ of each session to ensure that initial adaptation processes present in this period would not influence the results (Van Ee, 2009). For each experimental session, the perceptually stable periods, i.e., periods of consecutive reoc- currence of the same percept, were identified as follows. The first of a train of at least 10 consecutive reports of the same percept was considered the start of the first perceptually stable period. After that, a perceptually stable period was considered terminated as soon as the opposite, nonstabilized percept was reported on 10 consecutive presentations, marking the start of a new stabilized period for this opposite percept. This definition allows the nonstabilized percept to occur occasionally ( $<10$ times consecutively) within a stabilized period of the other percept, in line with the known perceptual dynamics of the rotating globe and other bistable stimuli (Leopold et al., 2002; Brascamp et al., 2009; de Jong et al., 2012b). The limit of 10 repetitions was considered reasonable based on previous studies (Leopold et al., 2002; Brascamp et al., 2009; de Jong et al., 2012b), but we repeated our analyses using more extreme limits of either 5 or 60 repetitions and found equivalent results (data not shown).

In our analysis, we discarded all presentations in which the nonstabilized percept was reported. Furthermore, we discarded all perceptual alternations, i.e., presentations in which perception had changed relative to the preceding presentation. Together, these two categories amounted to $3.9 \%$ of the presentations on average across participants. We chose this strategy because perceptual alternations from one presentation to the next may evoke additional neural processes (Kornmeier and Bach, 2004, 2005, 2006; Pitts et al., 2007, 2009). These processes are outside of our present scope, because we focus on long-term history effects rather than those that act from one presentation to the next. To ensure that our specific manner of discarding presentation-to-presentation perceptual alternations did not critically affect our results, we repeated our analyses while discarding not one presentation after each nonstabilized percept but instead discarding the entire period if it was not perfectly stable. This yielded equivalent results (see Results; Fig. 2C).

EEG data recording and preprocessing. The participants were seated in an electronically and acoustically shielded room. EEG was sampled at $2048 \mathrm{~Hz}$ and recorded with 64 silver/silver chloride flat-type active electrodes (Active Two System; Biosemi) positioned at standard locations on an elastic cap (Quickcap; Neurosoft) and referenced to an additional active electrode (Common Mode Sense) during recording. Two of the electrodes in the cap provided an active ground. An additional electrode was placed at the right mastoid, and horizontal and vertical electrooculograms were measured.

Preprocessing of the EEG data was performed using BrainVision Analyzer 2.0 (Brain Products) and included a $0.1-20 \mathrm{~Hz}$ bandpass filter, a 50 $\mathrm{Hz}$ Notch filter, and referencing to the right mastoid for all electrodes. Epochs time locked to the onset of the stimulus were extracted from the continuous data. Artifacts attributable to eye movements were removed (algorithm by Gratton et al., 1983). Epochs containing EEG amplitudes more than $\pm 50 \mu \mathrm{V}$ or within-epoch amplitude differences $>75 \mu \mathrm{V}$ were removed from the analysis. We also checked for recording failure by excluding epochs with $<0.5 \mu \mathrm{V}$ amplitude differences within a $200 \mathrm{~ms}$ window (abnormally low activity) and epochs with amplitude steps per sample point $>50 \mu \mathrm{V}$ (abnormal recording gradient), although this seldom occurred. Baseline correction was performed relative to a $100 \mathrm{~ms}$ prestimulus interval.

Selection of regions of interest. Activity changes in sensory brain regions have been related to stimulus repetition (Krekelberg et al., 2006), percept repetition (de Jong et al., 2012b), perceptual learning/memory (Henson et al., 2000; Schwartz et al., 2002; Furmanski et al., 2004; Kourtzi et al., 2005), and presentation-to-presentation perceptual alternations during ambiguous visual stimulation (Kornmeier et al., 2004; Pitts et al., 2009; Sterzer et al., 2009). Conversely, activity in the frontal and parietal brain regions has also been associated with presentation-to-presentation perceptual alternations (Pitts et al., 2009; Sterzer et al., 2009; Pitts and Britz, 2011) and attention/mnemonic processing of sensory information (Desimone, 1996; Pasternak and Greenlee, 2005). Interestingly, ERPs derived from scalp EEGs measured during ambiguous perception are also modulated at anterior and posterior electrodes (Kornmeier and Bach, 2004, 2005, 2006; Pitts et al., 2007, 2008, 2009; Khoe et al., 2008). This is in line with the involvement of posterior and anterior regions in perceptual processing, although the inverse problem makes it hard to justify conclusions about which brain regions from which these scalp ERP modulations originate. 
A

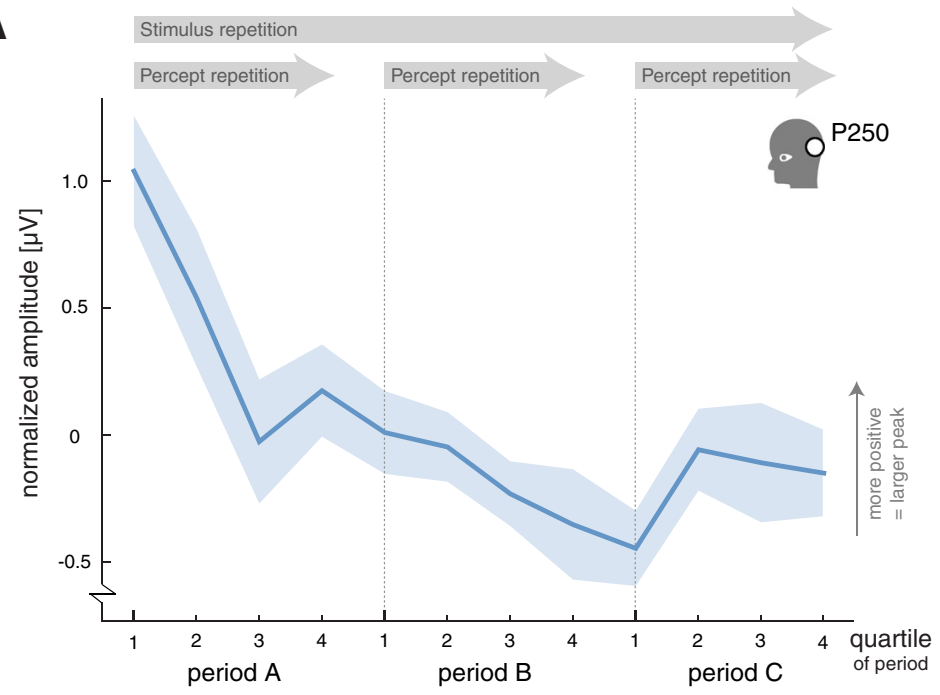

B

Stimulus repetition

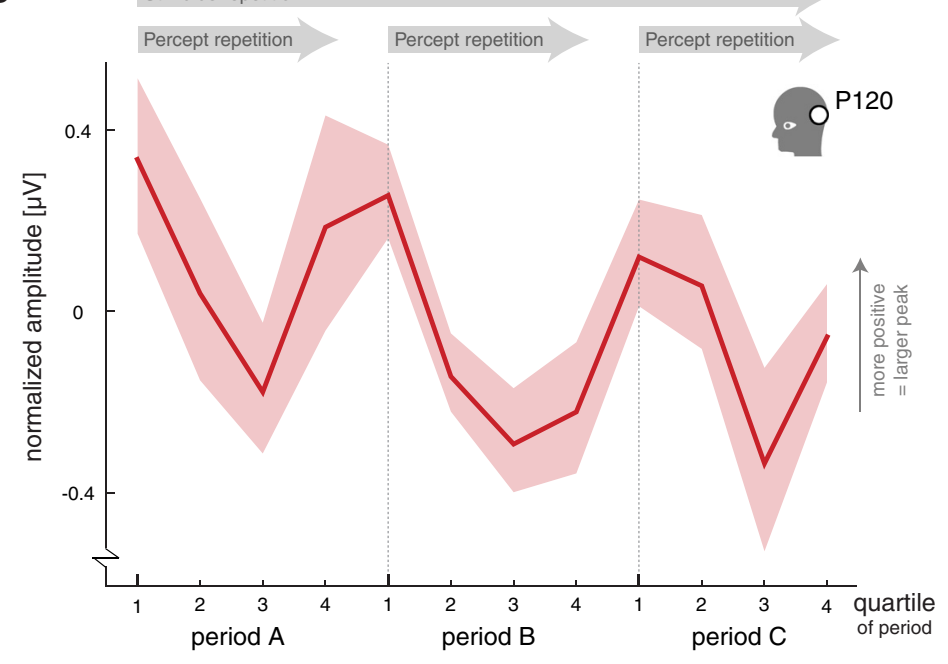

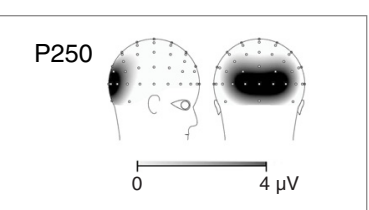

individual participants $\mathrm{C}^{\mathrm{P} 250}$

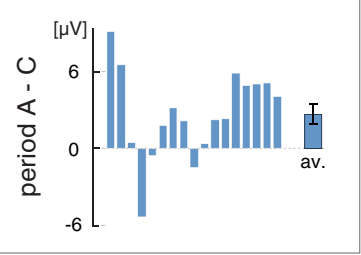

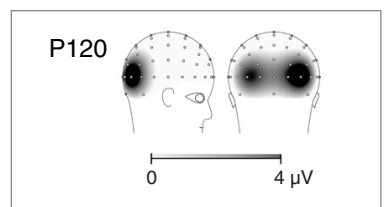

individual participants. $\mathrm{C}^{\mathrm{P} 120}$

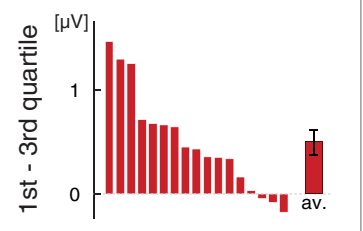

C perfectly stable periods:
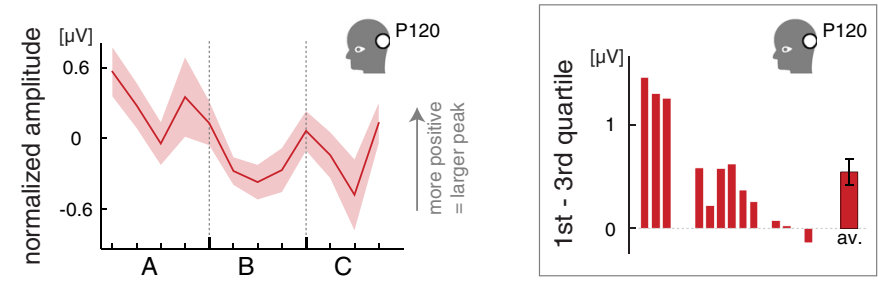

Figure 2. The influence of stimulus repetition and percept repetition on peak values in the posterior region of interest. $\boldsymbol{A}$, The influence of stimulus repetition on the amplitude of the posterior P250 peak. During an experimental session, the amplitude gradually decreased over time, regardless of the experienced percept (i.e., regardless of the changes in perception between the 3 perceptually stable periods that constituted a session; see Fig. 1 ; $n=17$; shading indicates \pm 1 SEM). The right top inset shows the topographical map of the P250 peak (EEG signal measured over the scalp between 200 and $250 \mathrm{~ms}$ after stimulus onset; darker shades indicate more positive amplitude; $n=17)$. The bottom inset shows the difference in P250 amplitude between periods A and C (averaged across quartiles) for individual participants. $\boldsymbol{B}$, The influence of percept repetition on the amplitude of the posterior P120 peak. Within each perceptually stable period, the amplitude decreased from the first to third quartiles and slightly recovered from the third to fourth quartiles ( $n=17$; shading indicates $\pm 1 \mathrm{SEM})$. This fall-and-rise pattern of the P120 amplitude was present within each period and resulted in an oscillating pattern across periods. Because this modulation developed within rather than across periods, we contribute it to percept repetition and not to stimulus repetition. The data thus reflect an early peak in the ERP, occurring $\sim 120 \mathrm{~ms}$ after stimulus onset, whose amplitude is modulated across many stimulus presentations, constituting an oscillatory pattern over the course of many minutes. Importantly, this oscillatory pattern developed relative to the perceptual time course rather than relative to real time or the absolute amount of stimulus presentations, given that the perceptually stable periods (and thus the quartiles) contained varying absolute numbers of stimulus presentations. The right top inset shows the topographical map of the P120 peak (EEG signal measured over the scalp between 100 and 150 ms after stimulus onset; darker shades indicate more positive amplitude; $n=17$ ). The bottom inset shows the difference in P120 amplitude between the first and third quartiles for individual participants, averaged across periods $A, B$, and C. The order in which the participants are depicted is the same as in the bottom inset of $A$. $C$, The influence of percept repetition on the amplitude of the posterior P120 peak when the analysis included the perfectly stable periods only ( 0 reports of the nonstabilized percept; $n=12$; shading indicates \pm 1 SEM). A fall-and-rise pattern occurred within each period, similar to the graph presented in $\boldsymbol{B}$, suggesting that the recovery in P120 amplitude from the third to fourth quartiles was not related to the sporadic occurrence of the nonstabilized percept in quartile 4 . The inset on the right shows the difference in P120 amplitude between the first and third quartiles for individual participants, averaged across periods A, B, and C (perfectly stable periods only; same order of participants as the bottom insets of $\boldsymbol{A}$ and $\boldsymbol{B}$ ). 
Across the above-mentioned ERP investigations into ambiguous perception, there is a remarkable consistency regarding the electrodes that responded to ambiguous stimuli per se and to manipulations of ambiguous perception. Using different stimuli (e.g., binocular and perceptual rivalry) and different types of perceptual manipulations (bottom-up and top-down, stimulus driven and attentional in nature), the same electrodes were reported repeatedly to show affected ERPs. Given this consistency in the reported electrode sites of interest across ambiguous stimuli and across perceptual manipulations, we expected that these same electrodes would also reflect the long-term perceptual manipulations investigated in the present study. Therefore, we selected a posterior region and an anterior region of interest for additional analysis of the ERPs (Fig. 1D; choice of electrodes based on Kornmeier and Bach, 2004, 2005, 2006; Pitts et al., 2007, 2008, 2009; Khoe et al., 2008). For the posterior region of interest, we averaged the signals of electrodes $\mathrm{O} 1, \mathrm{O} 2$, $\mathrm{Oz}, \mathrm{P} 5, \mathrm{P} 6, \mathrm{PO} 3, \mathrm{PO} 4, \mathrm{PO} 7, \mathrm{PO} 8$, and $\mathrm{POz}$, and for the anterior region of interest, we averaged the signals of electrodes AFz, F1, F2, FC1, FC2, FCz, and Fz. We did not consider the individual electrodes but analyzed the averaged signal in the predefined regions of interest, thereby limiting the number of analyzed spatial locations to two (limitation of multiple comparisons problem). As an additional precaution against any false-positive results making their way into our data, we repeated our analyses of the posterior activity using a more assumption-free method of selecting the region of interest. Specifically, we found similar results when we replaced our posterior region of interest with one that comprised the entire back half of the scalp, i.e., the averaged signal of all electrodes posterior to $\mathrm{Cz}$.

In the above-mentioned existing literature, the latencies of the ERPs that reflected perceptual manipulations were relatively early. Considering the present study, the behavioral definition of longer-term perceptual stability also points to a critical contribution of short-latency neural processing. Perceptual stability influences current perception (see Introduction), and this can be done effectively only when processes that lead up to, i.e., precede, the perceptual decision are changed. Given these considerations, we were mainly interested in - and restricted our analyses to-short-latency ERPs. Regardless of stimulus/percept history, the time-locked epochs in the posterior region typically showed three shortlatency peaks: (1) P120; (2) N170; and (3) P250 (Fig. 1E, left graph). In the anterior region, the N150, P200, and P300 peaks were present in the typical ERP (Fig. 1E, right graph). Peak names were chosen such that $\mathrm{N}$ and $\mathrm{P}$ indicate negative and positive deflections, respectively, and the number indicates the approximate across-participant latency of the peak relative to stimulus onset.

We used these peaks to guide additional analyses and searched for their session-specific latencies within the following intervals after stimulus onset (intervals based on visual data inspection): 95-170, 150-225, and 210-285 ms for the posterior P120, N170, and P250 peaks, respectively, and $120-195,160-235$, and 265-340 ms for the anterior N150, P200, and P300 peaks, respectively. Within each of these intervals, the sessionspecific peak latency was defined as the time point at which the maximum (minimum for $\mathrm{N}$ peaks) voltage occurred in the session-averaged ERP. When the outcome of this automated definition did not reflected a true peak/extremum, we manually selected a local extremum instead (if present; this occurred only for the anterior P200 peak in two participants). Based on additional observations of the data (see Results), we analyzed the posterior N50 and anterior P50 components (Fig. 1E), applying the same method as described above. We used a 30-80 ms interval after stimulus onset for these components. A local extremum was manually selected for six participants (in one or two of their sessions) regarding the N50 and for four participants (in one of their sessions) regarding the P50 component. A control analysis in which we excluded, per peak, all sessions with an unclear or manually adjusted peak value yielded equivalent results (data not shown), indicating that the used method of manual peak selection did not critically influence our results.

Additional processing of EEG data. Additional analysis was performed using MATLAB (MathWorks). The critical idea underlying our approach was to compare ERPs across presentations of the stimulus both within and across perceptually stable periods. The effects of stimulus repetition can accumulate during a session, across perceptually stable periods, because perceptual changes are irrelevant with regard to stimu- lus repetition. Conversely, the effects of percept repetition can accumulate within a perceptually stable period but not across perceptually stable periods that are separated by a change in perception. To test changes in the EEG data both within and across perceptually stable periods, we identified the three perceptually stable periods $\mathrm{A}, \mathrm{B}$, and $\mathrm{C}$ as described above. We discarded experimental sessions in which one or more of these periods did not last long enough to provide enough repetitions $(<60)$ for calculation of meaningful ERPs (for five participants, one session was excluded, and for three participants, two sessions were excluded, leaving 2.0 sessions on average per participant).

To implement our analysis, we split each period into four quartiles that each contained $25 \%$ of the presentations of that period. Depending on the length of the period, the quartiles of different periods could thus contain varying absolute numbers of stimulus presentations. Our procedure yielded four consecutive time bins in each period, which could be compared to investigate percept repetition, and 12 consecutive time bins across the three periods that together spanned the entire experimental session ( 3 periods $\times 4$ quartiles $=12$ time bins). The consecutive periods could be compared to investigate stimulus repetition. The 12 consecutive time bins will be referred to as A1, A2, A3, A4, B1, B2, B3, B4, C1, C2, C3, and C4, respectively, and ERPs recorded within each time bin were averaged.

For each of the 12 time bins separately, we calculated the amplitude of each of the above-defined ERP components (represented in Fig. $1 E$ ) by determining the mean voltage in a $30 \mathrm{~ms}$ time window that was centered on the session-wide latency defined previously for that component (see above). We also determined the peak latency of each component for each time bin by searching for the maximum or minimum voltage within this $30 \mathrm{~ms}$ window. The data were then averaged across all sessions of a given participant and, on average, reflected the recordings of 95.8 stimulus presentations per time bin (after discarding data).

Statistical analysis was performed using PASW Statistics 18. Unless indicated otherwise, we performed a repeated-measures ANOVA over participants, with perceptually stable period (period A, B, or C) and quartile of perceptually stable period (quartile $1,2,3$, or 4 ) as within factors $(\alpha=0.05)$. A Greenhouse-Geisser correction was applied. As we expected, for the effects of stimulus repetition to accumulate during a session, across the perceptually stable periods, a main effect of period would indicate an effect of stimulus repetition. The effects of percept repetition were expected to accumulate within a perceptually stable period, across the repeated occurrences of the stabilized percept, and might thus be reflected in a main effect of quartile but not of period. In addition, we performed a Pearson's correlation analysis in some instances to get a better understanding of effect sizes. These cases are clearly indicated in the text.

\section{Results}

The present study investigated modulations of the neural response in a posterior and an anterior region of interest (Fig. 1D) under conditions of repeated perception of, and stimulation with, the same ambiguous stimulus. Our protocol was designed to elicit three distinct and consecutive periods of stable perception across repetitions of the same ambiguous stimulus, referred to as periods $\mathrm{A}, \mathrm{B}$, and $\mathrm{C}$ (Fig. 1C). The behavioral and EEG data in each perceptually stable period were binned per quartile, with each quartile containing 25\% of the presentations of that period. We investigated changes across the stable periods, which may reflect the influence of stimulus repetition, and changes within the stable periods, across the quartiles, which may reflect the influence of percept repetition (period $\times$ quartile ANOVA; see Materials and Methods).

\section{Behavioral results}

All participants experienced prolonged periods of perceptual stability that lasted on average $4.6 \pm 0.3 \mathrm{~min}$ (SEM; equivalent to 229 presentations). Periods A, B, and C did not differ in average duration $\left(F_{(1.9,28.4)}=1.6, p=0.2\right.$, effect of duration in repeated- 
measures ANOVA over participants). The nonstabilized perceptual interpretation was on average seen in $2.5 \pm 0.9 \%$ (mean \pm SEM) of the presentations (these presentations were excluded from the analysis; see Materials and Methods). The percentage of nonstabilized percepts did not differ between periods A, B, and C $\left(F_{(1.7,27.8)}=0.6, p=0.5\right.$, main effect of period), but within the periods, a higher proportion of nonstabilized percepts was reported in the fourth quartile compared with the other three quartiles $(1.5,1.2,1.6$, and $6.1 \%$ in quartiles $1-4$, respectively; $F_{(1.6,25.9)}=7.8, p=0.004$, main effect of quartile; all $F_{(1,16)}>9.1$, all $p \leq 0.008$, per-quartile tests of difference from fourth quartile).

Stimulus repetition: modulation of late perceptual processing Stimulus repetition influenced the amplitudes and latencies of ERP components at $\sim 200 \mathrm{~ms}$ after stimulus onset, as is illustrated by the modulation of the posterior P250 peak (Fig. 2A). The P250 peak showed a gradually decreasing amplitude during an experimental session $(0.7 \mu \mathrm{V}$ average difference between periods $\mathrm{A}$ and C; $\left.F_{(1.4,22.5)}=8.7, p=0.004\right)$. Note that this change occurred slowly over the course of several minutes, because an experimental session lasted on average almost 14 min (see above).

The effect of stimulus repetition on the P250 peak is nicely illustrated by the difference wave between the posterior ERPs of stable periods $\mathrm{A}$ and $\mathrm{C}$, which shows a clear deviation around the timing of the posterior P250 peak (Fig. 3C, blue line). There were additional effects of stimulus repetition, which are summarized in table form in Figure 4C. In general, increased latencies over stimulus repetitions were found somewhat earlier than the P250 in both the posterior and anterior regions of interest (posterior N170 peak: $3.2 \mathrm{~ms}$ delay, $F_{(1.4,23.1)}=6.7, p=0.01$, effect of period; anterior P200 peak: 5.2 ms delay, $F_{(1.9,29.8)}=10.9, p=$ 0.0004, effect of period). An additional amplitude modulation followed later in the anterior region of interest (the $\mathrm{P} 300$ peak: 1.4 $\mu \mathrm{V}$ increase, $F_{(1.8,28.9)}=8.2, p=0.002$, effect of period). Interestingly, the amplitude was gradually increased in the anterior region (P300 peak), whereas it was decreased in the posterior region $\left(\mathrm{P} 250\right.$ peak). A period $\times$ quartile interaction $\left(F_{(3.8,60.9)}=\right.$ $4.7, p=0.003)$ indicated that the amplitude of the posterior P250 peak was extra large in the very first time bin (quartile 1 of period A) compared with all other time bins (Fig. 2A; the effect of quartile was only significant in period A). To test this directly, we performed a post hoc alternative ANOVA in which we treated the 12 consecutive time bins that constituted an experimental session as one factor (i.e., repeated-measures ANOVA over participants with time bin as the only within factor, $\alpha=0.05$, a GreenhouseGeisser correction was applied). The 12 time bins indeed differed from each other $\left(F_{(3.8,61.3)}=5.1, p=0.002\right)$, and partial testing revealed that the first time bin differed from all but the second time bin (second time bin: $F_{(1,16)}=3.2, p=0.09$, other time bins: all $F_{(1,16)} \geq 6.7$, all $p \leq 0.02$ ). The extra large $\mathrm{P} 250$ amplitude in the first time bin suggests that initial adaptation was greater than later adaptation in the posterior region.

Percept repetition: modulation of early perceptual processing Compared with stimulus repetition, the modulations related to percept repetition occurred markedly early in the ERP (Figs. 3C, 4 , compare $C, D)$. One of the earliest effects of percept repetition occurred on the posterior P120 peak (Fig. 2B). The P120 component is common in visual ERPs. It usually occurs between 100 and $150 \mathrm{~ms}$ after stimulus onset and is thought to reflect basic perceptual processing. Across the four quartiles of each perceptually stable period, the P120 showed a systematic amplitude change, which repeated during each consecutive stable period, and was manifested in a significant effect of quartile $\left(F_{(2.5,40.7)}=4.3, p=\right.$ 0.01 ). However, rather than there being a monotonic effect of quartile, we observed a decrease in the amplitude of the P120 peak from the first to the third quartile of a perceptually stable period $\left(F_{(1,16)}=18.1, p<0.001\right.$, partial test between the first and third quartiles; $0.50 \pm 0.12 \mu \mathrm{V}$, mean \pm SEM amplitude difference), followed by a slight increase in each fourth quartile ( 0.24 $\mu \mathrm{V}$ relative to third quartile). The fourth quartile differed from neither the first quartile $\left(F_{(1,16)}=2.5, p=0.1\right)$ nor the third quartile $\left(F_{(1,16)}=2.5, p=0.1\right)$. Below, an additional analysis is presented to help characterize this fall-and-rise pattern, and it is discussed further in Discussion. First, however, note that the pattern was present within each perceptually stable period, creating the oscillating curve seen in Figure $2 B$, and that the difference in P120 amplitude between the first and third quartiles was very robust across participants (Fig. 2B, bottom inset).

The difference in P120 amplitude between the first and third quartiles was not stronger in longer-lasting or more stable periods, because it did not correlate with the duration of the perceptually stable periods ( $r=-0.1$ averaged across participants, $t_{(16)}$ $=-0.5, p=0.6)$ nor with the general prevalence of the nonstabilized percept $\left(r=0.0\right.$ averaged across participants, $t_{(16)}=0.0$, $p=1.0 ; t$ test across participants). The increase in P120 amplitude from the third to fourth quartiles might be related to the higher proportion of nonstabilized percepts reported in the fourth quartile compared with the other three quartiles (see above). However, an analysis of only the perfectly stable periods (i.e., periods in which the nonstabilized percept was never reported) provided no support for this idea. Instead, this analysis revealed the same fall-and-rise pattern as obtained when including all data (Fig. $2 C ; F_{(2.2,23.7)}=2.6, p=0.095$, effect of quartile; $F_{(1,11)}=12.8, p=0.004$, partial test between the first and third quartiles; fourth quartile differed from neither the first quartile nor the third quartile, both $F_{(1,16)}<2.4$, both $p \geq 0.2$ ).

Additional effects of percept repetitions beyond the P120 peak are summarized in table form in Figure $4 D$ and illustrated for the posterior region of interest in Figure 3, $B$ and $C$, by a comparison between the average ERP waveforms for the first and third quartiles, respectively (averaged across perceptually stable periods). In the posterior region, we did not observe amplitude modulations on any peaks later than the P120 (Fig. 3B). There was a fall-andrise latency modulation on the posterior N170 peak, meaning that the latency decreased from the first to the third quartile and increased again in the fourth quartile $\left(F_{(2.6,41.5)}=4.0, p<0.05\right.$, effect of quartile; normalized latencies for quartiles $1-4$ averaged across periods: $0.48,-1.56,-0.90$, and $1.22 \mathrm{~ms}$; Fig. $4 D$ ). Combined with the latency effect of stimulus repetition reported above for the N170 (Fig. 4C), this peak thus showed a superposition of both these effects. In the anterior region, an effect of percept repetition did not appear until well after the posterior effects, namely only on the P200 peak at $\sim 200 \mathrm{~ms}$ after stimulus onset. The amplitude of the anterior P200 peak was larger in the first quartile of each period than in the following quartiles (the first quartile differed from all others: all $F_{(1,16)}>8.4$, all $p \leq 0.01$; $F_{(2.1,33.7)}=6.1, p=0.005$, effect of quartile). The pattern of results within each period was thus L-shaped rather than U-shaped (normalized amplitudes for quartiles 1-4 averaged across periods: $0.59,-0.50,-0.28$, and $-0.41 \mathrm{~ms}$; Fig. $4 D$ ).

\section{Percept repetition: modulation of N50 peak}

Above we reported that the amplitude of the posterior P120 peak increased from the first to the third quartiles of every stable pe- 
A EFFECT OF STIMULUS REPETITION

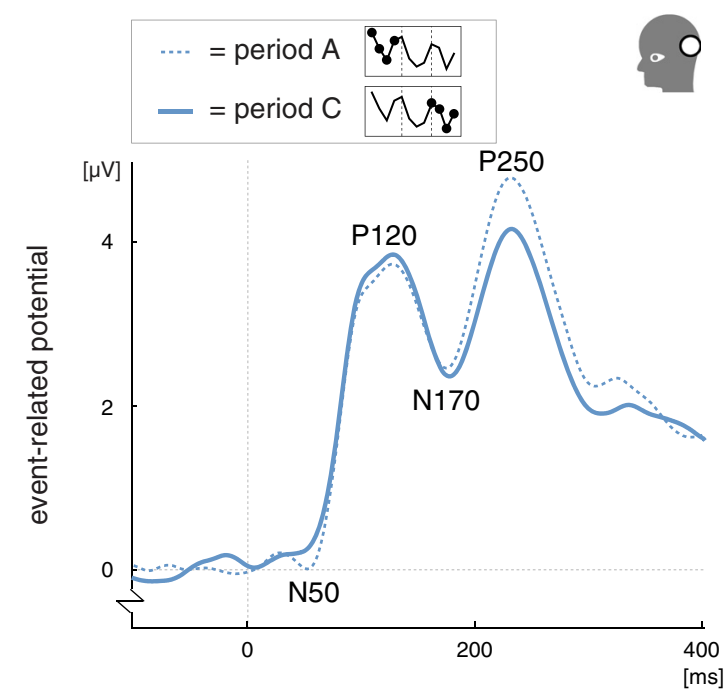

B

C $\quad-1$ st quartile - 3rd quartile (effect of percept repetition) - = period $\mathrm{A}$ - period $\mathrm{C}$ (effect of stimulus repetition)
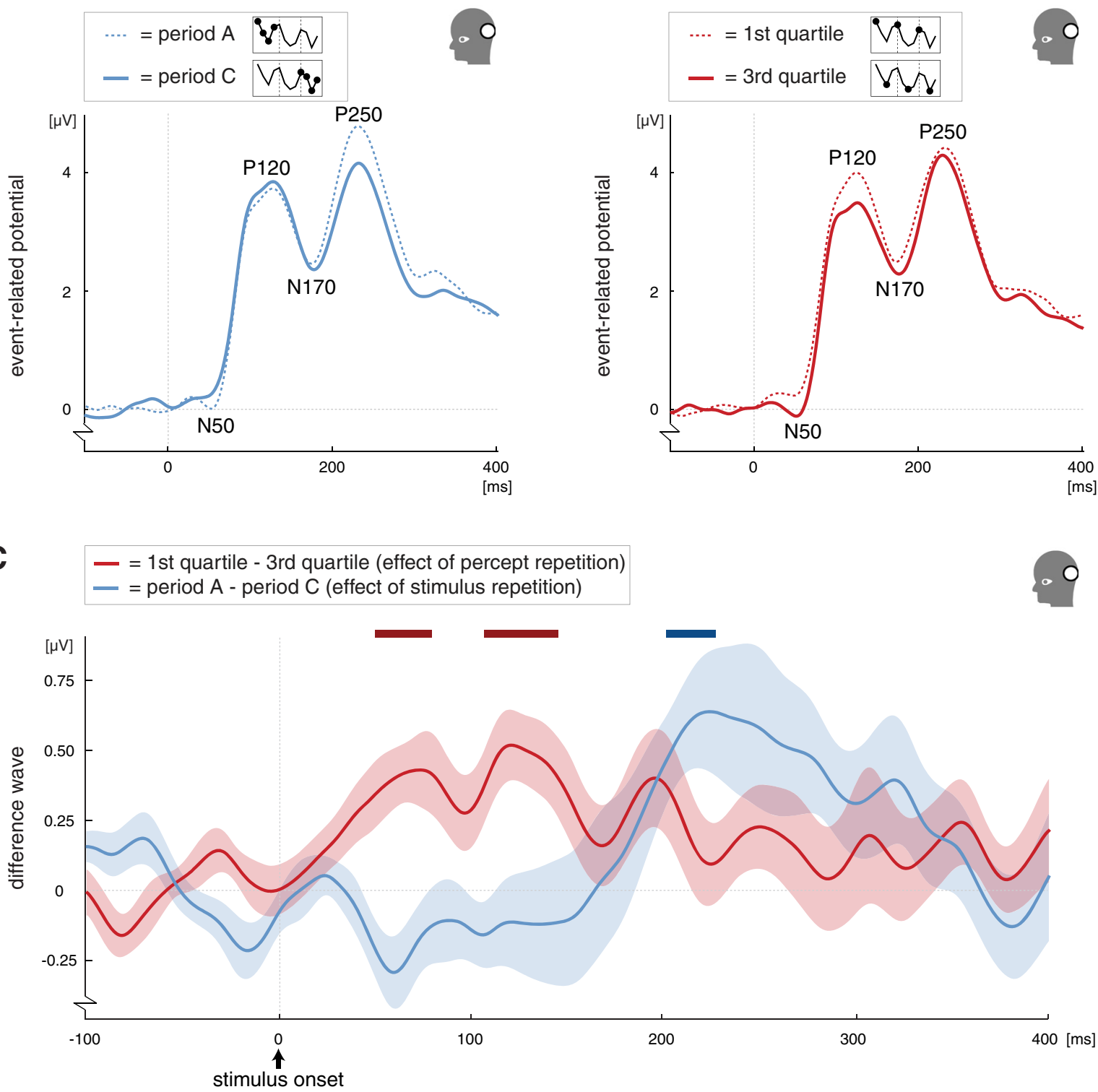

Figure 3. The influence of stimulus repetition and percept repetition on the waveform of the posterior ERP. A, Waveform of ERPs measured in the posterior region of interest in the first period (period A; dashed line) and the last period (period C; solid line), showing the influence of stimulus repetition on the posterior P250 peak. Both waveforms are averaged across the four quartiles of the respective period (as indicated by the diagram in the legend; $n=17$ ). $\boldsymbol{B}$. Waveform of ERPs measured in the posterior region of interest in the first (dashed line) and third (solid line) quartiles, showing the modulation of the posterior N50 and P120 peaks. Both waveforms are averaged across the periods A, B, and C (as indicated by the diagram in the legend; $n=17$ ). C, Difference wave illustrating that, in the posterior region of interest, the effect of percept repetition occurred shortly after stimulus onset (red line) and the effect stimulus repetition occurred later in the ERP (blue line; $n=17$; shading indicates \pm 1 SEM). These effects are in line with the peak amplitude analyses reported in Figure 2 and 4, which indicated that the N50 and P120 peaks are affected by percept repetition and the P250 peak is affected by stimulus repetition. Specifically, the red line here represents the difference between the ERPs measured in the first and third quartiles (see $\boldsymbol{B}$; first quartile - third quartile; averaged across periods $A, B$, and C), and the blue line represents the difference between the ERPs measured in the first and last period (see $A$; period $A$ - period C; averaged across the four quartiles of each period). Statistical analysis of continuous waves like these is not straightforward, because there is a strong temporal correlation between successive time points. For illustration purposes only, we performed $t$ tests on each time point of these difference waves using a conservative $\alpha$ of 0.01 . The horizontal bars at the top of the graph represent the time points at which the $t$ tests indicated a difference from 0 for the effects of percept repetition (dark red bars) and stimulus repetition (dark blue bar).

riod (Figs. $2 B, 3 B$ ). The difference between the posterior ERP waveforms from the first and third quartiles (averaged across periods) indeed shows a deviation from zero, coinciding with the timing of the P120 peak (Fig. 3C, red line). However, inspection of Figure 3, $B$ and $C$, suggests that this difference already existed earlier on in the ERP, around the latency of the negative deflection preceding the P120. Hereafter, we will refer to this deflection as the N50 peak. When we analyzed the amplitude and latency of the N50, we found a fall-and-rise amplitude modulation similar to that of the P120 (Fig. $4 A ; F_{(2.1,33.9)}=4.4, p=0.02$, effect of quartile; $F_{(1,16)}=16.3, p=0.001$, partial test between the first and third quartiles; fourth quartile differed from neither the first quartile nor the third quartile, both $F_{(1,16)}<3.0$, both $\left.p>0.1\right)$. As was the case for the P120 peak, the difference in N50 amplitude between the first and third quartiles was very robust across participants (Fig. $4 A$, inset), and it averaged $0.39 \pm 0.10 \mu \mathrm{V}$ (mean \pm SEM).

Thus, the observed effects of percept repetition on the posterior ERP started to arise as early as $50 \mathrm{~ms}$ after stimulus onset. The 
A

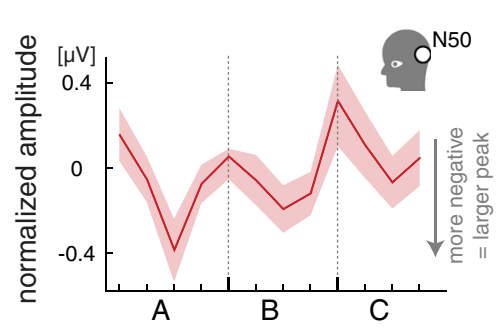

B

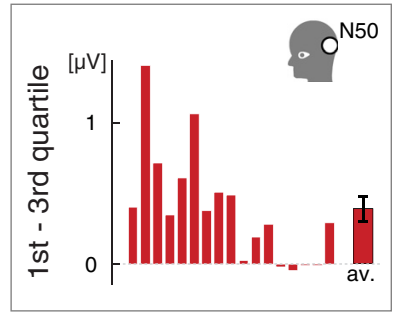

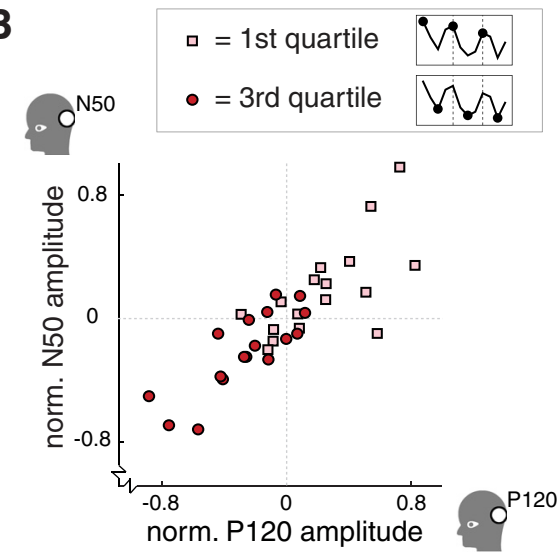

C

\begin{tabular}{|c|c|c|c|c|c|c|c|c|}
\hline $\begin{array}{l}\text { STIMULUS } \\
\text { REPETITION }\end{array}$ & $\begin{array}{l}\text { ? } \\
\text { P50 }\end{array}$ & N50 & $\begin{array}{l}00 \\
\text { P120 }\end{array}$ & $\begin{array}{l}0 \\
\text { N150 } \\
\text { N150 }\end{array}$ & N170 & $\begin{array}{l}0 \\
\circ \\
\text { P200 }\end{array}$ & $\therefore 0$ & $\begin{array}{l}0 \\
: \\
\text { P300 }\end{array}$ \\
\hline ERP amplitude & - & - & ${ }^{\circ}$ & - & - & - & *d & * $\mathrm{i}$ \\
\hline ERP latency & . & - & - & - & * $\mathrm{i}$ & * $\mathrm{i}$ & - & - \\
\hline
\end{tabular}

D

\begin{tabular}{|c|c|c|c|c|c|c|c|c|}
\hline $\begin{array}{l}\text { PERCEPT } \\
\text { REPETITION }\end{array}$ & $\begin{array}{l}0 \\
: \\
\text { P50 }\end{array}$ & $\begin{array}{l}\triangle \mathrm{O} \\
\mathrm{N} 50\end{array}$ & & $\begin{array}{l}0 \\
: \\
\text { N150 }\end{array}$ & N170 & $\begin{array}{l}0 \\
: \\
\text { P200 }\end{array}$ & $\begin{array}{l}\triangle 0 \\
\text { P250 }\end{array}$ & $\begin{array}{l}0 \\
0 \\
\text { P300 }\end{array}$ \\
\hline ERP amplitude & - & *u & *u & - & - & $* \mathrm{~L}$ & - & - \\
\hline ERP latency & - & - & - & - & *u & - & . & - \\
\hline
\end{tabular}

Figure 4. The influence of percept repetition on the posterior N50 peak and an overview of the influences of stimulus repetition and percept repetition on ERPs. $A$, The influence of percept repetition on the amplitude of the posterior N50 peak, showing a fall-and-rise pattern within each period similar to the modulation of the P120 peak (see Fig. $2 B ; n=17$; shading indicates \pm 1 SEM). Note that the $\mathrm{N} 50$ is a negative deflection, meaning that smaller amplitudes (voltages) actually indicate a larger (more negative) peak and a lower starting point of the upstroke in activity leading to the P120 peak. The inset on the right shows the difference in N50 amplitude between the first and third quartiles for individual participants, averaged across periods A, B, and C (same order of participants as the bottom insets of Fig. 2A-C). B. The amplitudes of the posterior N50 (vertical axis) and P120 (horizontal axis) peaks for the first (pink squares) and third (red circles) quartiles separately, averaged across periods. For both peaks, the amplitudes were relatively high (i.e., above average) in the first quartile and relatively small (i.e., below average) in the third quartile. Also, participants with a high P120 amplitude tended to have a high N50 amplitude as well. The difference between the first and third quartiles in the amplitude of early posterior peaks reflects the influence of percept repetition. Participants with a large effect size for the P120 also tended to have a large effect size for the N50 (compare the bottom insets in Fig. $2 B$ and 4A). Note that the N50 is a negative deflection, meaning that smaller peak amplitudes (voltages) actually indicate a larger (more negative) peak, whereas for the P120 peak, being a positive deflection, smaller amplitudes indicate a smaller (less positive) peak. C, Overview of the effects of stimulus repetition on ERP peak values in both the posterior (white background) and the anterior (gray background) region of interest (open circle in the diagrams indicate the appropriate region; see Fig. 1D). From left to right, the peaks are chronologically ordered relative to stimulus onset. Peaks that were significantly influenced by stimulus repetition are indicated with an asterisk. In both the anterior and posterior regions, there was a late latency modulation ( $\sim 200$ ms after stimulus onset), followed by a late amplitude modulation (" $\mathrm{i}$ " and " $\mathrm{d}$ " indicate gradual increases and decreases over the course of a session, respectively; Figs. 2A, 3A). D, Overview of the effects of percept repetition on ERP peak values in the posterior (white background) and anterior (gray background) regions of interest (layout and symbols as in $C$. There was an early posterior amplitude modulation related to percept repetition that emerged at $\sim 50 \mathrm{~ms}$ after stimulus onset (Fig. 3 B, C and influenced the N50 and P120 peaks (Figs. 2B, 4A, respectively). The amplitude of the early posterior N50 and P120 peaks decreased from the first quartile to the third quartile of each perceptually stable period and partially recovered during the fourth quartile (Fig. $2 B$ ). Such fall-and-rise effects are indicated with " $u$ " in the table, whereas " $\mathrm{L}$ " indicates a fall without the rise in the fourth quartile.

effects of stimulus repetition, in comparison, occurred much later, starting at $\sim 200 \mathrm{~ms}$ after stimulus onset (Figs. $3 A, C, 4 C$ ). To ensure that this early effect of percept repetition could not be attributed to fluctuations during the baseline interval, we analyzed activity during the $100 \mathrm{~ms}$ baseline interval preceding stimulus onset. For this additional analysis, we placed our $30 \mathrm{~ms}$ analysis window in the early $(-100$ to $-70 \mathrm{~ms})$, middle ( -65 to $-35 \mathrm{~ms}$ ), and late ( -30 to $0 \mathrm{~ms}$ ) parts of the baseline interval and performed baseline correction on the remainder of the original baseline interval (which spanned -100 to 0 ms relative to stimulus onset). The results show that the effect of percept repetition was absent before stimulus onset, because there was no amplitude effect of percept repetition in any of these segments of the base- line interval (all $F<1.3$, all $p>0.3$, effect of quartile; all $F_{(1,16)}<$ 2.7 , all $p>0.1$, partial test between the first and third quartiles). Moreover, with these alternative baseline corrections, the amplitude modulations of the N50 and P120 were still present (all $F \geq$ 3.0 , all $p \leq 0.06$, effect of quartile; all $F_{(1,16)}>12.0$, all $p \leq 0.003$, partial test between the first and third quartiles). Thus, the reported early posterior effect of percept repetition arose after stimulus onset and could not be attributed to fluctuations during the baseline interval.

The magnitudes of the effect of percept repetition (i.e., the difference between the first and third quartiles) for the N50 and P120 peaks correlated across participants $\left(r=0.70, t_{(15)}=3.7\right.$, $p=0.002)$, meaning that participants with a large effect size for 
the P120 also tended to have a large effect size for the N50 (compare the insets in Figs. $2 B$ and $4 A$ showing the effect sizes of the individual participants). This association between the P120 and the N50 was also present when the peak amplitudes in the first and third quartiles were considered separately (Fig. 4B). In the first quartile, participants with a high P120 amplitude also tended to have a high N50 amplitude $\left(r=0.67, t_{(15)}=3.5, p=0.003\right)$, although the amplitudes of both peaks were relatively high (above average) for all participants. In the third quartile, the peak amplitudes were generally small (below average), and, across participants, the smaller P120 amplitudes were associated with the smaller N50 amplitudes $\left(r=0.82, t_{(15)}=5.6, p=0.0001\right.$; for the data of individual participants, see Fig. $4 B$ ). Note that the N50 is a negative deflection, meaning that smaller peak amplitudes (voltages) actually indicate a larger (more negative) peak, whereas for the P120 peak, being a positive deflection, smaller amplitudes indicate a smaller (less positive) peak. Because the N50 peak precedes the P120 peak, smaller N50 amplitudes might constitute a lower starting point of the upstroke in activity leading to the P120 peak. The positive correlation between the two peaks is consistent with this idea.

Using a post hoc paired $t$ test, we compared the magnitude of the effect of percept repetition in the first and second experimental sessions per participant. For both the N50 and P120 peaks, the effect sizes did not differ between the two sessions (N50 peak: $t_{(10)}$ $=1.1, p=0.3 ; \mathrm{P} 120$ peak: $t_{(10)}=0.6, p=0.6$, paired $t$ tests across participants). Finally, to assess the spatial specificity of the effect of percept repetition at $\sim 50 \mathrm{~ms}$ after stimulus onset, we analyzed the anterior P50 peak, which coincides in time with the posterior N50 peak. Contrary to the posterior N50, the anterior P50 was not influenced by percept repetition (Fig. 4D; P50 amplitude: $F_{(2.7,43.5)}=1.0, p=0.4$, effect of quartile; $F_{(1,16)}=2.8, p>0.1$, partial test between the first and third quartiles).

\section{Overview of results}

The participants viewed an ambiguous structure-from-motion stimulus that was presented intermittently and reported seeing the same perceptual interpretation for several minutes at a time (Fig. $1 A-C$ ). Within such a minutes-long perceptually stable period, the amplitude of the P120 peak, which is known to reflect early perceptual processing, decreased from the first to the third quartiles of each period and slightly increased again from the third to the fourth quartiles (Fig. 2B). This fall-and-rise amplitude modulation associated with percept repetition emerged shortly after stimulus onset in the posterior region of interest (50 ms, posterior N50 peak; Figs. $3 B, 4 A$, overview in $D$ ). The influences of stimulus repetition emerged later in the ERP $(200 \mathrm{~ms}$; Fig. $3 A, C)$ in both the posterior and anterior regions of interest (overview in Fig. 4C) and consisted of gradual changes in peak latencies and amplitudes over the course of an entire experimental session, across the perceptually stable periods (see P250 peak; Fig. 2A).

\section{Discussion}

We investigated modulations in cortical activity while participants viewed an intermittently presented ambiguous stimulus. In our experimental design, minutes-long sequences of perceptual repetitions were interspersed with occasional changes in perception, whereas the stimulus itself remained unchanged (Fig. 1A$C)$. These changes in perception allowed us to dissociate the co-occurring aftereffects of previous stimulation and previous perception, because the former accumulated throughout the session and the latter only within the perceptually stable periods.

\section{Stimulus repetition}

During the experimental sessions, which lasted $\sim 14$ min, a gradual delay arose of late ERP components (150-250 ms after stimulus onset; Figs. $2 A, 3 A$ ). This modulation did not depend on perceived interpretation of the stimulus, because it occurred across, rather than within, the perceptually stable periods. It may reflect a reduction in processing speed attributable to either a gradual buildup of neuronal adaptation for the stimulus or a gradual increase in the attention required to maintain focus on the task.

Stimulus repetition was also accompanied by a gradual amplitude increase in the anterior scalp region (P300 peak), perhaps reflecting an increase in attention (Luck et al., 2000; Khoe et al., 2008) or in familiarity of object representations (Henson et al., 2004; Guo et al., 2007).

Previous research has described a positive deflection with similar latency, present only when a stimulus is consciously perceived (the P3b; Dehaene and Changeux, 2011). We did not find percept-dependent effects on the P300. However, in our experiment, the stimulus was always consciously perceived and, accordingly, the P300 was always present. In contrast to the increased amplitude of the anterior P300 across stimulus repetitions, the posterior scalp region showed a progressive, apparently saturating, decrease in amplitude (P250 peak; Fig. 2A), possibly reflecting adaptation or fatigue (Kovács et al., 2006; Heinrich, 2007).

We focused on effects accumulating across several minutes. It is possible that different effects are present on shorter timescales, for example, between two consecutive stimulus presentations. These short-term effects may be saturated on the long timescale investigated here and, therefore, invisible in our analysis.

\section{Percept repetition}

The most notable influence of percept repetition was present on the posterior N50 and P120 peaks (50-140 ms after stimulus onset; Figs. $2 B, 3 B, 4 A$ ), thus preceding the above-discussed influences of stimulus repetition (Fig. $3 C$ ). The modulation was absent in the anterior region (Fig. 4D). A control analysis argued against an explanation in terms of changes in the baseline interval. The early posterior N50 and P120 peaks reflect perceptual processing and are modulated by basic stimulus features, such as spatial frequency (Pitts et al., 2010), luminance (Wijers et al., 1997), and contrast (Musselwhite and Jeffreys, 1982).

The P120 peak is thought to originate from extrastriate and ventral occipito-temporal cortices (Di Russo et al., 2002). Its amplitude showed a striking fall-and-rise pattern during perceptually stable periods, involving a gradual decrease from the first to the third quartiles $(75 \%)$ of the period and a slight increase during the last quartile (25\%). This U-shaped effect repeated in each perceptually stable period, creating an oscillatory pattern across periods (Fig. $2 B$ ). Note that this pattern developed relative to the perceptual time course rather than relative to real time, given that the perceptually stable periods varied in duration.

The observed fall-and-rise pattern may reflect varying stability of the dominant percept. Previous studies have indicated that perceptual stability gradually accumulates over the course of a stabilized period (like a perceptual "memory") but is reduced again near the end of the period, shortly before stabilization of the opposite percept begins (Brascamp et al., 2008, 2009). The gradual P120 amplitude decrease we observed from the first to the third quartiles (Fig. $2 B$ ) may be related to the initial increase in stability and possibly associated with sparser encoding and/or neural adaptation (Krekelberg et al., 2006). In turn, the slight increase in P120 amplitude in the fourth quartile (Fig. 2B) could 
be related to the eventual destabilization. Similar to the mechanism of motion opponency (Petersen et al., 1985; Krekelberg et al., 2006), this increase in amplitude could be associated with weakened inhibition onto, and increased responses in, neurons that prefer the opposite, suppressed percept (Hock et al., 1996; Klink et al., 2010; de Jong et al., 2012a). Using the metaphor of a (noisy) two-attractors model (Braun and Mattia, 2010; Kornmeier and Bach, 2012), the attractor for the stabilized percept initially becomes increasingly more stable/favorable, whereas near the end of a period, the favorability of the other attractor starts increasing.

The N50 peak showed a similar amplitude modulation as the P120 peak (Fig. 4A). Whereas the P120 peak is affected by attention and probably by short-term (presentation-to-presentation) perceptual history, the N50 peak is not (attention: Wijers et al., 1997; Martínez et al., 1999, 2001; Luck et al., 2000; short-term history: Kornmeier and Bach, 2005, 2006; Pitts et al., 2007, 2011). The N50 peak is believed to reflect bottom-up processing (Arroyo et al., 1997; Foxe and Simpson, 2002). The anatomical source of scalp EEG activity is indeterminate, but based on previous literature, we see two plausible anatomical sources of the N50 modulation: (1) early activation of the motion-sensitive mediotemporal area (MT/visual cortical area 5; Inui and Kakigi, 2006; Brascamp et al., 2010); and/or (2) the striate primary visual cortex (V1), which is a substantial contributor to EEG activity at this early latency (Clark et al., 1995; Martínez et al., 1999). One way to dissociate these options is to compare upper and lower visual field stimulation, because early ERP deflections can change polarity between upper and lower visual field stimulation when they originate in striate visual cortex but not when they originate in MT (Clark et al., 1995; Pitzalis et al., 2012). Additionally, it would be interesting to compare moving ambiguous figures, like the one used here, with nonmoving ambiguous figures, for example, binocular rivalry of orthogonal gratings, because the latter is likely to activate MT less strongly and V1 more strongly than the former. Note that the temporal coincidence of the stimulus-driven early posterior peaks (N50 and P120) with the perception-driven modulations discussed here does not necessarily mean that the same neural generators underlie both (Kornmeier et al., 2011). Still, the early onset of the modulations (50 ms after stimulus onset) suggests a change in the stimulus-driven, bottom-up response.

\section{Possible mechanisms}

Three timescales are important in understanding our results. The first is whether modulations occur early or late in the ERP (relative to stimulus onset), which may be related to early or late in the processing hierarchy and to bottom-up versus top-down processing. Generally, we found that percept repetition modulated early ERP components (at 50-140 ms), whereas stimulus repetition modulated late ERP components (at $150-300 \mathrm{~ms}$ ).

The second timescale concerns perceptual history over several seconds, for example, between successive presentations. We equated the immediate perceptual history (from one presentation to the next) by analyzing only perceptual repetitions. Previous studies have compared presentation-to-presentation alternations with repetitions and reported modulations starting from $130 \mathrm{~ms}$ after stimulus onset or much later (O'Donnell et al., 1988; Kornmeier and Bach, 2004, 2005, 2006; Pitts et al., 2007, 2008, 2009). Some reported a P120 modulation, potentially related to changes in spatial attention (Pitts et al., 2007), but none reported a modulation of the N50 peak. By design, there were few perceptual alternations in our data, precluding replication of these findings.

The third timescale concerns the minutes-long perceptually stable periods, whose occurrence cannot be explained exclusively by presentation-to-presentation priming but depends on an accumulation of percept history across minutes (Brascamp et al., 2008, 2009; Pearson and Brascamp, 2008). We report the abovediscussed fall-and-rise modulation of early posterior ERPs within such perceptually stable periods (Fig. $2 B$ ). This modulation developed relative to the perceptual time course rather than relative to real time or the amount of stimulus repetitions. By distinguishing these three timescales we can see the following: (1) the present study investigated long-term perceptual history (third timescale) rather than short-term history (second timescale); and (2) the effects of this long-term perceptual history (third timescale) occur strikingly early in the ERP (first timescale; 50-140 ms after stimulus onset).

Logically, perceptual history can only influence later perception if it is implemented in neural processing that precedes or constitutes the perceptual decision. Considering the early latency and posterior scalp location of our effects, we tentatively propose the following interpretation of our results. When perceiving an ambiguous stimulus, a perceptual "mnemonic trace" is left in the bottom-up response properties of neurons in early visual areas that differentiate between the possible interpretations of the stimulus (see possible neuronal mechanisms in the studies by Crist et al., 2001; Karmarkar and Dan, 2006). For our stimulus, these could include neurons selective for motion direction and depth (Pastukhov and Braun, 2013; Pastukhov et al., 2013). These altered bottom-up responses then lead to modulations of early ERP components during later stimulus presentations, explaining why this modulation appears soon after stimulus onset. In this view, perceptual stability accumulating across many presentations leaves a mnemonic trace that affects future perceptual decisions.

Although we propose a mnemonic trace that takes effect in a bottom-up way, we do not exclude the possibility that additional, potentially top-down, processing contributes to the buildup of the mnemonic trace across presentations, for example, indirectly by shaping the observer's perceptual experience. Indeed, perception of our stimulus plausibly involves feedback activity (Blake and Logothetis, 2002), and profound late activations of early visual regions could reflect such feedback activity (150-400 ms after stimulus onset; Martínez et al., 2001; Pitts and Britz, 2011; Pitzalis et al., 2012). Higher-order visual, parietal and frontal regions implicated in perceptual stabilization (de Jong et al., 2012b) and perceptual reversals (Sterzer et al., 2009; Kanai et al., 2011) could be involved. Regardless of the extent to which bottom-up or top-down factors determined perceptual decisions on preceding encounters with the stimulus, we suggest that the mnemonic trace left by preceding perceptual decisions affects current processing in a bottom-up manner, thereby constituting an early bias in perceptual decision-making toward the currently prevailing percept.

We focused on modulations soon after stimulus onset and regarded an ERP analysis most suitable considering its temporal precision, sensitivity to stimulus-evoked responses, and high signal-to-noise ratio. However, ERPs have the limitation of focusing on stimulus-locked effects. In future studies a time-frequency analysis of similar data may reveal important additional information, especially regarding long-term trends and feedback signals that may not be phase-locked to stimulus onset. Induced gamma oscillations, although they are too slow to influence the 
perceptual decision process (typically occurring 200-300 ms after stimulus onset), could be crucial for the proposed feedback activations. Additionally, it should be mentioned that the present study is explorative in nature, without much previous constraint on the data patterns of interest. This has allowed us to identify results not observed previously, but it also means that these results call for replication in studies constrained by our findings.

\section{Conclusions}

We found that very early posterior activity starting at $\sim 50 \mathrm{~ms}$ after stimulus onset was associated with percept repetition, suggesting that the information gained through previous perceptual experience is incorporated in the perceptual decision process via modification of the bottom-up visual response. We propose that, while viewing an ambiguous stimulus, feedback projections to early visual regions can modulate the response properties of these regions such that the perceptual decision process is biased in favor of the stabilized percept on future encounters with this stimulus.

\section{References}

Arroyo S, Lesser RP, Poon WT, Webber WR, Gordon B (1997) Neuronal generators of visual evoked potentials in humans: visual processing in the human cortex. Epilepsia 38:600-610. CrossRef Medline

Blake R, Logothetis N (2002) Visual competition. Nat Rev Neurosci 3:1321. CrossRef Medline

Brascamp JW, Knapen TH, Kanai R, Noest AJ, van Ee R, van den Berg AV (2008) Multi-timescale perceptual history resolves visual ambiguity. PLoS One 3:e1497. CrossRef Medline

Brascamp JW, Pearson J, Blake R, van den Berg AV (2009) Intermittent ambiguous stimuli: implicit memory causes periodic perceptual alternations. J Vis 9(3):3 1-23. CrossRef

Brascamp JW, Kanai R, Walsh V, van Ee R (2010) Human middle temporal cortex, perceptual bias, and perceptual memory for ambiguous threedimensional motion. J Neurosci 30:760-766. CrossRef Medline

Braun J, Mattia M (2010) Attractors and noise: twin drivers of decisions and multistability. Neuroimage 52:740-751. CrossRef Medline

Chopin A, Mamassian P (2012) Predictive properties of visual adaptation. Curr Biol 22:622-626. CrossRef Medline

Clark VP, Fan S, Hillyard SA (1995) Identification of early visual evoked potential generators by retinotopic and topographic analyses. Hum Brain Mapp 2:170-187.

Clifford CW, Webster MA, Stanley GB, Stocker AA, Kohn A, Sharpee TO, Schwartz O (2007) Visual adaptation: neural, psychological and computational aspects. Vision Res 47:3125-3131. CrossRef Medline

Crist RE, Li W, Gilbert CD (2001) Learning to see: experience and attention in primary visual cortex. Nat Neurosci 4:519-525. CrossRef Medline

Dehaene S, Changeux JP (2011) Experimental and theoretical approaches to conscious processing. Neuron 70:200-227. CrossRef Medline

de Jong MC, Knapen T, van Ee R (2012a) Opposite influence of perceptual memory on initial and prolonged perception of sensory ambiguity. PLoS One 71:e30595. CrossRef Medline

de Jong MC, Kourtzi Z, van Ee R (2012b) Perceptual experience modulates cortical circuits involved in visual awareness. Eur J Neurosci 36:37183731. CrossRef Medline

Desimone R (1996) Neural mechanisms for visual memory and their role in attention. Proc Natl Acad Sci U S A 93:13494-13499. Medline

Di Russo F, Martinez A, Sereno MI, Pitzalis S, Hillyard SA (2002) Cortical sources of the early components of the visual evoked potential. Hum Brain Mapp 15:95-111. CrossRef Medline

Foxe JJ, Simpson GV (2002) Flow of activation from V1 to frontal cortex in humans. A framework for defining "early" visual processing. Exp Brain Res 142:139-150. CrossRef Medline

Furmanski CS, Schluppeck D, Engel SA (2004) Learning strengthens the response of primary visual cortex to simple patterns. Curr Biol 14:573578. CrossRef Medline

Gratton G, Coles MG, Donchin E (1983) A new method for off-line removal of ocular artifact. Electroencephalogr Clin Neurophysiol 55:468-484. CrossRef Medline
Guo C, Lawson AL, Jiang Y (2007) Distinct neural mechanisms for repetition effects of visual objects. Neuroscience 149:747-759. CrossRef Medline

Heinrich SP (2007) A primer on motion visual evoked potentials. Doc Ophthalmol 114:83-105. CrossRef Medline

Henson RN, Rylands A, Ross E, Vuilleumeir P, Rugg MD (2004) The effect of repetition lag on electrophysiological and haemodynamic correlates of visual object priming. Neuroimage 21:1674-1689. CrossRef Medline

Henson R, Shallice T, Dolan R (2000) Neuroimaging evidence for dissociable forms of repetition priming. Science 287:1269-1272. CrossRef Medline

Hock HS, Schöner G, Hochstein S (1996) Perceptual stability and the selective adaptation of perceived and unperceived motion directions. Vision Res 36:3311-3323. CrossRef Medline

Inui K, Kakigi R (2006) Temporal analysis of the flow from V1 to the extrastriate cortex in humans. J Neurophysiol 96:775-784. Medline

Kanai R, Carmel D, Bahrami B, Rees G (2011) Structural and functional fractionation of right superior parietal cortex in bistable perception. Curr Biol 21:R106-R107. CrossRef Medline

Karmarkar UR, Dan Y (2006) Experience-dependent plasticity in adult visual cortex. Neuron 52:577-585. CrossRef Medline

Khoe W, Mitchell JF, Reynolds JH, Hillyard SA (2008) ERP evidence that surface-based attention biases interocular competition during rivalry. J Vis 8(3):18 1-11. CrossRef

Klink PC, Brascamp JW, Blake R, van Wezel RJ (2010) Experience-driven plasticity in binocular vision. Curr Biol 20:1464-1469. CrossRef Medline

Kornmeier J, Bach M (2004) Early neural activity in Necker-cube reversal: evidence for low-level processing of a gestalt phenomenon. Psychophysiology 41:1-8. CrossRef Medline

Kornmeier J, Bach M (2005) The Necker cube: an ambiguous figure disambiguated in early visual processing. Vision Res 45:955-960. CrossRef Medline

Kornmeier J, Bach M (2006) Bistable perception-along the processing chain from ambiguous visual input to a stable percept. Int J Psychophysiol 62:345-349. CrossRef Medline

Kornmeier J, Bach M (2012) Ambiguous figures: what happens in the brain when perception changes but not the stimulus. Front Hum Neurosci 6:51. CrossRef Medline

Kornmeier J, Pfaffle M, Bach M (2011) Necker cube: stimulus-related (lowlevel) and percept-related (high-level) EEG signatures early in occipital cortex. J Vis 11(9):12. CrossRef Medline

Kourtzi Z, Betts LR, Sarkheil P, Welchman AE (2005) Distributed neural plasticity for shape learning in the human visual cortex. PLoS Biol 3:e204. CrossRef Medline

Kovács G, Zimmer M, Bankó E, Harza I, Antal A, Vidnyánszky Z (2006) Electrophysiological correlates of visual adaptation to faces, body parts in humans. Cereb Cortex 16:742-753. CrossRef Medline

Krekelberg B, Boynton GM, van Wezel RJ (2006) Adaptation: from single cells to BOLD signals. Trends Neurosci 29:250-256. CrossRef Medline

Leopold DA, Wilke M, Maier A, Logothetis NK (2002) Stable perception of visually ambiguous patterns. Nat Neurosci 5:605-609. CrossRef Medline

Long GM, Toppino TC (2004) Enduring interest in perceptual ambiguity: alternating views of reversible figures. Psychol Bull 130:748-768. CrossRef Medline

Luck SJ, Woodman GF, Vogel EK (2000) Event-related potential studies of attention. Trends Cogn Sci 4:432-440. CrossRef Medline

Maier A, Wilke M, Logothetis NK, Leopold DA (2003) Perception of temporally interleaved ambiguous patterns. Curr Biol 13:1076-1085. CrossRef Medline

Martínez A, Anllo-Vento L, Sereno MI, Frank LR, Buxton RB, Dubowitz DJ, Wong EC, Hinrichs H, Heinze HJ, Hillyard SA (1999) Involvement of striate and extrastriate visual cortical areas in spatial attention. Nat Neurosci 2:364-369. CrossRef Medline

Martínez A, Di Russo F, Anllo-Vento L, Sereno MI, Buxton RB, Hillyard SA (2001) Putting spatial attention on the map: timing and localization of stimulus selection processes in striate and extrastriate visual areas. Vision Res 41:1437-1457. CrossRef Medline

Musselwhite MJ, Jeffreys DA (1982) Pattern-evoked potentials and Bloch's law. Vision Res 22:897-903. CrossRef Medline

Noest AJ, van Ee R, Nijs MM, van Wezel RJ (2007) Percept-choice sequences driven by interrupted ambiguous stimuli: a low-level neural model. J Vis 7(8):10. CrossRef

O'Donnell BF, Hendler T, Squires NK (1988) Visual evoked potentials to 
illusory reversals of the necker cube. Psychophysiology 25:137-143. CrossRef Medline

Orbach J, Ehrlich D, Heath HA (1963) Reversibility of the Neckercube: I. An examination of the concept of "satiation of orientation." Percept Motor Skills 17:439-458. CrossRef Medline

Pasternak T, Greenlee MW (2005) Working memory in primate sensory systems. Nat Rev Neurosci 6:97-107. CrossRef Medline

Pastukhov A, Braun J (2008) A short-term memory of multi-stable perception. J Vis 8(13):7 1-14. CrossRef

Pastukhov A, Braun J (2013) Structure-from-motion: dissociating perception, neural persistence, and sensory memory of illusory depth and illusory rotation. Atten Percept Psychophys 75:322-340. CrossRef Medline

Pastukhov A, Füllekrug J, Braun J (2013) Sensory memory of structurefrom-motion is shape-specific. Atten Percept Psychophys 75:1215-1229. CrossRef Medline

Pearson J, Brascamp J (2008) Sensory memory for ambiguous vision. Trends Cogn Sci 12:334-341. CrossRef Medline

Pearson J, Clifford CW (2005) Mechanisms selectively engaged in rivalry: normal vision habituates and rivalrous vision primes. Vision Res 45:707714. CrossRef Medline

Petersen SE, Baker JF, Allman JM (1985) Direction-specific adaptation in area MT of the owl monkey. Brain Res 346:146-150. CrossRef Medline

Pitts MA, Britz J (2011) Insights from intermittent binocular rivalry and EEG. Front Hum Neurosci 5:107. CrossRef Medline

Pitts MA, Martinez A, Hillyard SA (2010) When and where is binocular rivalry resolved in the visual cortex? J Vis 10(14):pii 25. CrossRef
Pitts MA, Nerger JL, Davis TJ (2007) Electrophysiological correlates of perceptual reversals for three different types of multistable images. J Vis 7(1):6. CrossRef

Pitts MA, Gavin WJ, Nerger JL (2008) Early top-down influences on bistable perception revealed by event-related potentials. Brain Cogn 67:11-24. CrossRef Medline

Pitts MA, Martínez A, Stalmaster C, Nerger JL, Hillyard SA (2009) Neural generators of ERPs linked with Necker cube reversals. Psychophysiology 46:694-702. CrossRef Medline

Pitzalis S, Strappini F, De Gasperis M, Bultrini A, Di Russo F (2012) Spatiotemporal brain mapping of motion-onset VEPs combined with fMRI and retinotopic maps. PLoS One 7:e35771. CrossRef Medline

Schwartz S, Maquet P, Frith C (2002) Neural correlates of perceptual learning: a functional MRI study of visual texture discrimination. Proc Natl Acad Sci U S A 99:17137-17142. CrossRef Medline

Sterzer P, Kleinschmidt A, Rees G (2009) The neural bases of multistable perception. Trends Cogn Sci 13:310-318. CrossRef Medline

Thompson P, Burr D (2009) Visual aftereffects. Curr Biol 19:R11-R14. CrossRef Medline

Van Ee R (2009) Stochastic variations in sensory awareness are driven by noisy neuronal adaptation: evidence from serial correlations in perceptual bistability. J Opt Soc Am A 26:2612-2622. CrossRef Medline

Wijers AA, Lange JJ, Mulder G, Mulder LJ (1997) An ERP study of visual spatial attention and letter target detection for isoluminant and nonisoluminant stimuli. Psychophysiology 34:553-565. CrossRef Medline 